\title{
Oral cancer: Current role of radiotherapy and chemotherapy
}

\author{
Shao-Hui Huang ${ }^{1}$, Brian O'Sullivan ${ }^{2}$ \\ ${ }^{1} \mathrm{MD}, \mathrm{MRT}(\mathrm{T})$, Assistant Professor \\ ${ }^{2} \mathrm{MD}$, Professor Department of Radiation Oncology, the Princess Margaret Hospital, University of Toronto
}

Correspondence:

Rm. 5-624, Princess Margaret Hospital

610 University Ave, Toronto, Ontario

Canada. M5G $2 M 9$

Brian.OSullivan@rmp.uhn.on.ca

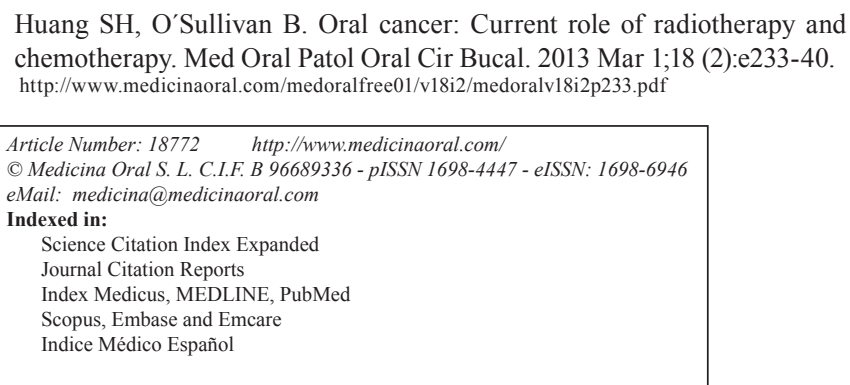

\begin{abstract}
The term oral cavity cancer (OSCC) constitutes cancers of the mucosal surfaces of the lips, floor of mouth, oral tongue, buccal mucosa, lower and upper gingiva, hard palate and retromolar trigone. Treatment approaches for OSCC include single management with surgery, radiotherapy [external beam radiotherapy (EBRT) and/or brachytherapy], as well as adjuvant systemic therapy (chemotherapy and/or target agents); various combinations of these modalities may also be used depending on the disease presentation and pathological findings. The selection of sole or combined modality is based on various considerations that include disease control probability, the anticipated functional and cosmetic outcomes, tumor resectability, patient general condition, and availability of resources and expertise. For resectable OSCC, the mainstay of treatment is surgery, though same practitioners may advocate for the use of radiotherapy alone in selected "early" disease presentations or combined with chemotherapy in more locally advanced stage disease. In general, the latter is more commonly reserved for cases where surgery may be problematic. Thus, primary radiotherapy \pm chemotherapy is usually reserved for patients unable to tolerate or who are otherwise unsuited for surgery. On the other hand, brachytherapy may be considered as a sole modality for early small primary tumor. It also has a role as an adjuvant to surgery in the setting of inadequate pathologically assessed resection margins, as does postoperative external beam radiotherapy \pm chemotherapy, which is usually reserved for those with unfavorable pathological features. Brachytherapy can also be especially useful in the reirradiation setting for persistent or recurrent disease or for a second primary arising within a previous radiation field. Biological agents targeting the epithelial growth factor receptor (EGFR) have emerged as a potential modality in combination with radiotherapy or chemoradiotherpy and are currently under evaluation in clinical trials.
\end{abstract}

Key words: Radiotherapy, chemoradiotherapy, oral cavity cancer, treatment. 


\section{Introduction}

In epidemiology studies, the term 'oral cancer' is sometimes employed to connote both oral cavity cancer and oropharyngeal cancer. However, these are different clinical entities and in contemporary practice often have different etiologies and are frequently managed differently. The latter largely occurs for reasons that pertain to local anatomy, functional outcome, and long-term toxicity, especially bone. This review will embrace the clinical definition of "oral cancer", as defined by the American Joint Committee on Cancer (AJCC) and the Union for International Cancer Control (UICC) in the tumor-node-metastasis (TNM) staging classification. This includes squamous cell carcinomas of the oral cavity (OSCC) originating from the mucosal lip, anterior two-thirds of the tongue (oral tongue), buccal mucosa, floor of mouth, hard palate, lower and upper alveolus and gingiva, and the retromolar trigone.

Treatment of OSCC includes single modality surgery, radiotherapy [external beam radiotherapy (EBRT) and/ or brachytherapy], or various combinations of these modalities with or without systemic therapy (chemotherapy and/or target agents). The selection of treatment is based on considerations of disease control, anticipated functional and cosmetic outcomes, and availability of resources and expertise. From a practical stand-point, the availability of reports largely dictates that we need to rely on retrospective case series and a few available randomized trials and several combined analysis that include meta-analysis data.

The mainstay of treatment for OSCC is usually surgery (1). EBRT with or without chemotherapy is generally employed in 3 situations: a) adjuvant to primary surgery to enhance loco-regional control (LRC) for cases with unfavorable pathological features, b) primary treatment for cases unable to tolerate or unsuited for surgery, and c) salvage treatment in the persistent or recurrent disease setting. Brachytherapy may be employed as a sole modality for early disease with a well-defined primary tumor, or as an adjuvant to surgery for cases with close or positive resection margins. Alternatively it may be used as a "boost" technique to the primary tumor in addition to EBRT (Table 1). Recently, epithelial grown factor receptor (EGFR) targeted therapy, such as cetuximab, has emerged as a promising treatment option in conjunction with EBRT to enhance disease control.

Table 1. Summary of Role of Radiotherapy and Chemoradiotherapy in Oral Cavity Cancer.

\begin{tabular}{|c|c|c|c|}
\hline & $\begin{array}{l}\text { External Beam } \\
\text { Radiotherapy (EBRT) }\end{array}$ & Chemotherapy & Interstitial Brachytherapy \\
\hline Primary setting & $\begin{array}{l}\text { - Early disease when patient } \\
\text { intolerant of surgery } \\
\text { - Early disease when } \\
\text { anticipated cosmetic } \\
\text { consequence of surgery is a } \\
\text { concern, especially for lip } \\
\text { cancer involving } \\
\text { commissure } \\
\text { - Unresectable disease, } \\
\text { usually combined with } \\
\text { chemotherapy } \\
\text { - Advanced disease for } \\
\text { patients intolerant of surgery } \\
\text { due to poor performance } \\
\text { status or comobidities }\end{array}$ & $\begin{array}{l}\text { - Advanced disease or } \\
\text { unresectable disease, } \\
\text { in combination with } \\
\text { radiotherapy }\end{array}$ & $\begin{array}{l}\text { Early and superficial well- } \\
\text { defined tumor located } \\
\text { more than } 5 \mathrm{~mm} \text { from the } \\
\text { mandible }\end{array}$ \\
\hline Adjuvant setting & $\begin{array}{l}\text { - Unfavorable pathological } \\
\text { features } \\
\text { - Combined with } \\
\text { chemotherapy for positive } \\
\text { resection margins and } \\
\text { extracapsular nodal } \\
\text { extension }\end{array}$ & $\begin{array}{l}\text { Combined with } \\
\text { radiotherapy for } \\
\text { positive resection } \\
\text { margins or } \\
\text { extracapsular nodal } \\
\text { extension }\end{array}$ & $\begin{array}{l}\text { Brachytherapy alone for } \\
\text { positive resection margins } \\
\text { - In combination with } \\
\text { external beam radiotherapy } \\
\text { to augment radiotherapy } \\
\text { dose to the high risk area }\end{array}$ \\
\hline Salvage setting & $\begin{array}{l}\text { Adjuvant treatment after } \\
\text { salvage surgery } \\
\text { Primary treatment modality, } \\
\text { usually combined with } \\
\text { chemotherapy if further } \\
\text { surgery is not feasible }\end{array}$ & $\begin{array}{l}\text { Combined with } \\
\text { radiotherapy }\end{array}$ & $\begin{array}{l}\text { - Especially useful for re- } \\
\text { irradiation: } \\
\text { - for persistent or } \\
\text { recurrent disease after } \\
\text { previous radiation, } \\
-2^{\text {nd }} \text { primary cancer } \\
\text { occurrence within } \\
\text { previous radiation field }\end{array}$ \\
\hline
\end{tabular}




\section{Postoperative Radiotherapy \pm Chemotherapy}

-Risk profile and indications for adjuvant treatment Primary surgery is the traditional approach for resectable OSCC in most centers. For patients with unfavourable pathological features, postoperative radiotherapy (PORT) or postoperative concurrent chemo-radiotherapy (POCRT) have been shown to improve LRC and survival in several clinical trials (2-4). General indications for PORT include: T3 or T4 tumor; compromised surgical resection margins $(<5 \mathrm{~mm}$ from the inked surface of the specimen); presence of lympho-vascular invasion (LVI) and/or peri-neural invasion (PNI); and positive lymph nodes with or without extracapsular invasion (ECE) (2,5).

The presence of multiple risk factors is common in OSCC. To understand the loco-regional recurrence risk profile, Langendijk, et al. studied 801 head-and-neck cancer patients (73\% of whom had OSCC) who underwent PORT in 1985-2000. They did not include their most favourable cases that did not require PORT in the report. A recursive partitioning analysis addressing loco-regional recurrence stratified patients into three risk groups: a) intermediate-risk: clear resection margins and no ECE, b) high-risk: T1, T2 and T4 tumor with close or positive margins or one pathological positive lymph node with ECE, c) very high-risk: T3 tumor with close or positive surgical margins or multiple pathological positive lymph nodes with ECE or an N3 neck (6). For the latter two groups, the 5-year LRC with PORT was unsatisfactory ( $78 \%$ and $58 \%$, respectively). The authors concluded that more intensive approaches, such as POCRT with concurrent chemotherapy should be considered for these two sub-groups.

Pathological stage I-II disease with sufficiently clear resection margins is generally considered low-risk and does not require PORT (7). Studies suggest that PNI alone appears to be non-predictive for recurrence $(8,9)$. However, the presence of LVI or microscopic tumor foci in muscle increased the risk of recurrence and PORT should be considered. Tumor thickness, or alternative synonyms such as "depth of invasion" or "tumor depth", has been consistently identified as a predictor for cervical lymph node metastasis (10). Recent studies have shown that pathological tumor thickness $\geq 4 \mathrm{~mm}$ combined with poorly differentiated pT1-2N0 OSCC tumors are associated with poor regional control and such patients may benefit from PORT (11).

The effectiveness of PORT for T1 or T2 primary with completely resected N1 disease is yet to be confirmed. Currently, there is an on-going European clinical trial evaluating the effectiveness of PORT in pT1-T2pN1 oral cavity and oropharyngeal cancers with clear resection margins (12).

The presence of microscopic positive margins and/or ECE is considered high-risk for recurrence. The addition of chemotherapy to PORT for these patients resulted in a $13 \%$ absolute reduction in loco-regional relapse at 5-years in the EORTC trial 22931 reported by Bernier et al. (13) and a 10\% absolute reduction at 2-years in the RTOG trial 9501 reported by Cooper, et al. (3). Other features may also be considered "high-risk". The RTOG 85-03 and 88-24 trials indicated the presence of 2 or more pathological positive lymph nodes as a high-risk feature for loco-regional failure (14). Some studies have also shown that multiple $(>2)$ minor risk factors combined with LVI were associated with poor prognosis (15-17) suggesting that more intensive regimens such as concurrent chemotherapy, may be justified in addition to PORT (Fig. 1).

-Definition of close resection margin

The definition of 'close' resection margins is generally accepted as tumor within $5 \mathrm{~mm}$ of the inked resection margin in formalin fixed surgical specimens (18). Several small retrospective studies suggested that the traditional margin of $5 \mathrm{~mm}$ may be too generous, especially when one consider the shrinkage that take place in the final surgical specimen; this may amount to as much as 40\% 50\% compared to fresh specimens (19). These authors suggested that a $2 \mathrm{~mm}$ inked margin as "cutoff" for the "close" margin definition is sufficient $(20,21)$. However, these findings are based on small retrospective studies and need confirmation.

The risk associated with an intra-operatively 'revised' margin following a positive resection margin excision has not been well studied. Compromised local control and disease-specific survival for those with intra-operative positive margin was described recently even though the final tumor margin was negative after revision (22). The latter study supports the adverse nature of an intraoperative positive margin regardless of final tumor margin, and PORT should be considered.

-Optimal surgery-to-radiotherapy interval

The optimal surgery-to-radiotherapy interval is controversial. A systematic review of published literature showed an increased odds ratio (2.9) for local recurrence in head and neck cancer patients whose PORT were started more than 6 weeks after surgery vs. those within 6 weeks of surgery (23). The optimal nature of a surgery-to-radiotherapy interval of "6 weeks" was also echoed in a recent OSCC series (24) but not confirmed by others $(5,25)$. Nevertheless, commencing PORT as soon as possible seems desirable but requires careful planning and multidisciplinary collaboration, and may not always be achievable when surgical complications are present. Furthermore, such complications are more likely following larger and more extensive surgical resection for more locally invasive lesions, larger tumors, and those with extensive lymph node involvement. Patients with such tumors are more likely to be candidates for intensive adjuvant treatments and the most likely to suffer from their omission. The greater prevalence of 


\begin{tabular}{|c|c|c|}
\hline & $\begin{array}{c}\text { Oral Cavity } \\
\text { Squamous Cell Carcinoma }\end{array}$ & \\
\hline $\begin{array}{l}\text { Low-risk (all): } \\
\text { - T1-T2 } \\
\text { - Clear resection margin ( } \geq 5 \\
\text { mm) } \\
\text { - no LVI } \\
\text { - no microscopic muscle } \\
\text { invasion }\end{array}$ & $\begin{array}{l}\text { Intermediate-risk (any): } \\
\text { - T3-T4 } \\
\text { - Close resection margin } \\
\text { - LVI } \\
\text { - PNI } \\
\text { - Positive lymph node(s) } \\
\text { without ECE }\end{array}$ & $\begin{array}{l}\text { High-risk (any): } \\
\text { - Positive resection } \\
\text { margin } \\
\text { - ECE }\end{array}$ \\
\hline$\nabla$ & $\nabla$ & $\downarrow$ \\
\hline $\begin{array}{l}\text { Treatment: } \\
\text { - Surgery alone } \\
\text { Expected Outcome: } \\
\text { - 5-year LRC: }>90 \% \\
\text { (Only retrospective data } \\
\text { available) }\end{array}$ & $\begin{array}{l}\text { Treatment: } \\
\text { - PORT } \\
\text { Expected Outcome: } \\
\text { - 5-year LRC: } ~ 78 \% \\
\text { - Treatment effect size: } \\
\text { (PORT vs. Surgery alone) } \\
-30 \% \text { difference in DFS } \\
-10 \% \text { difference in OS but } \\
\text { NS }\end{array}$ & $\begin{array}{l}\text { Treatment: } \\
\text { - POCRT } \\
\text { Expected Outcome: } \\
\text { - 5-year LRC: } \sim 80 \% \\
\text { - Treatment effect size: } \\
\text { (POCRT vs. PORT) } \\
-28 \% \text { difference in OS } \\
-42 \% \text { difference in LRC } \\
\text { - }\end{array}$ \\
\hline
\end{tabular}

Fig. 1. Summary of Risk Grouping and Role of Postoperative Radiotherapy +/- Chemotherapy.

Abbreviations: LVI: lympho-vascular invasion; ECE: extra-capsular invasion; PORT: postoperative radiotherapy; POCRT: postoperative chemoradiotherapy; LRC: locoregional control; DFS: disease-free survival; OS: overall survival; NS: not statistical significant

Note:

1. Crude estimates of expected outcomes were obtained from the following sources:

- Low-risk: Huang, et al. (8)

- Intermediate-risk: Langendjk, et al. (25),

- High-risk: Bernier, et al. (2) from the experimental arms of the combined report of RTOG \#9501 and EORTC \#22931

2. Treatment effect size:

- PORT vs. Surgery: Mishra, et al (55)

- POCRT vs. PORT: Bernier, et al (2)

more advanced cancer in the latter time cohort due to wound healing delay may also partly explain any putative adverse influence of delay in the initiation of PORT. Therefore, no arbitrary time limit has been scientifically established during which PORT must begin, or beyond which PORT has been shown not to have an effect (5). In essence, high risk cases should still be considered in circumstances where there has been delay in initiating radiotherapy due to the grave consequences of locoregional recurrence that might be prevented by the use of adjuvant treatment.

\section{Primary Radiotherapy \pm Chemotherapy with- out Surgery}

Primary radiotherapy with or without chemotherapy is not used routinely but may be deployed for the follow- ing reasons: a) in early stage disease to avoid anticipated functional and cosmetic defect, b) for unresectable disease, c) for high operative risk patients due to comorbidity or poor performance status, d) recurrent disease when previous multiple surgeries have been undertaken and further surgery would be technically improbable, and e) patient's preference. No prospective trial has directly compared primary surgery vs. primary radiotherapy in OSCC specifically. Two case series comparing RT vs. surgery suggested a lower LRC with primary radiotherapy compared to surgery approach $(26,27)$. However, these patients were mostly treated with less intensified treatment regimens and the retrospective nature of the studies questions whether case selection for both treatments was equal. Also, whether intensified treatment approaches, such as concurrent chemoradiotherapy, could improve outcome sufficiently to be 
comparable to surgery remains to be investigated. A subgroup analysis of 39 T4 OSCC with primary CRT from four multi-institutional phase II studies showed a 5 -year LRC rate of $75 \%$ (28); in turn this opens the potential for organ preservation approaches with CRT in patients with T4 OSCC.

In the meta-analysis of individual patient data from clinical trials comparing RT vs. CRT (MACH-NC) in locally advanced head and neck cancers, OSCC comprised $21 \%$ of cases (29). Result showed an improvement of survival in OSCC with CRT compared to RT alone ( $\mathrm{HR}=0.8)$. In the meta-analysis of individual patient data from clinical trials comparing hyper-fractionated or accelerated vs. conventional radiotherapy schedule (MARCH) (30), OSCC consisted of only $12.6 \%$ of cases. Again, intensified regimens, in this case altered fractionation radiotherapy, improved survival over conventional radiotherapy (hazard ratio $=0.8$ ) . The results from these two meta-analyses seem to suggest that for patient unable to receive primary surgery, treatment intensification by concurrent chemotherapy or altered fractionation RT may be considered.

\section{Interstitial Radiotherapy (Brachytherapy)}

Interstitial brachytherapy represents a traditional approach for OSCC and is an alternative to external beam radiotherapy (EBRT). Brachytherapy delivers radiotherapy by positioning radioactive sources in direct proximity to the tumor target area. The advantage of brachytherapy is its highly conformal dose distribution to a small target area by virtue of a rapid "fall-off" within surrounding normal tissue. It can be applied as a definitive treatment for early OSCC; as a complimentary treatment in combination with surgery; as a local "boost" in combination with EBRT to enhance the local dose to the immediate tumor region; or as a salvage option for small burden persistent or recurrent disease (31).

-Brachytherapy alone

No randomized trials have been performed comparing brachytherapy versus other conventional treatment for OSCC. Based on clinical experience, a consensus statement from GEC-ESTRO has recommended that brachytherapy alone could be used for T1-T2N0 oral mucosa $(<1.5 \mathrm{~cm}$ in thickness), oral tongue lesion, or floor of mouth lesions locate at least $5 \mathrm{~mm}$ from the mandible due to the high risk of inducing osteoradionecrosis (ORN). Brachytherapy is not suitable for T4 tumor with bone involvement (31). An additional concern about the use of brachytherapy alone for early OSCC is its inability to addressing occult neck disease. For example, an increased rate of late lymph node recurrence for clinical T1N0 OSCC has been reported following brachytherapy alone, especially in tumors exceeding 6 $\mathrm{mm}$ in thickness. The authors have consequently recommended prophylactic nodal irradiation in addition to brachytherapy for early-stage OSCC exceeding this thickness (32).

-Postoperative brachytherapy

Postoperative brachytherapy could be offered in T1-3 tumor with narrow or positive resection margins or LVI. A retrospective study of local tumor excision followed by postoperative interstitial brachytherapy with and without external radiotherapy has shown excellent locoregional control (33). In addition, brachytherapy can be delivered as an adjuvant "boost" to augment the radiation dose to a high risk area for advanced OSCC undergoing EBRT (34-37). An alternative approach is the use of simultaneous integrated boost IMRT but the relative value of both approaches remains to be determined.

Brachytherapy for re-irradiation

The feasibility of re-irradiation with EBRT after definitive EBRT is limited by concerns about excessive morbidity related to normal tissue tolerance. Therefore, surgical resection is often and appropriately presented as the main or potentially only curative option. However, carotid involvement in persistent disease is relatively common in recurrent disease and carotid artery resection carries significant risk including potential dramatic adverse sequelae, such as cerebrovascular event. Because of the ability to curtail the size of the irradiated volume, brachytherapy seems especially indicated to minimize the risk of severe complications in re-irradiation for persistent/recurrent disease or for new primary tumors located within previously irradiated volumes $(33,38,39)$.

-Brachytherapy delivery techniques

Commonly used radioactive sources are I-125 and Ir192. Considerable experience has been accumulated with low-dose rate (LDR) brachytherapy and its effectiveness for OSCC has been confirmed in large clinical series (40). Recently, high-dose rate (HDR) and pulseddose rate (PDR) brachytherapy have emerged as new brachytherapy delivery techniques offering the advantage of optimizing dose distribution by varying dwell times and employing computerized planning and delivery techniques. However, these techniques require the availability of particular expertise and resources that has affected their widespread adoption in many centers especially in settings with insufficient operating room resources and radiotherapy protection requirements.

\section{Biotherapy with Targeted Agent}

Emerging data also indicate that the epidermal growth factor (EGFR) and its signal transduction pathway play an important role in head and neck cancer. Overexpression of EGFR has been confirmed in OSCC and has been reported to be associated with a poor prognosis (41-43). The addition of a targeted agent, such as a monoclonal antibody EGFR inhibitor, has been reported to improve outcome over primary radiotherapy alone in 
head and neck cancers of the oropharynx, hypopharynx and larynx (44). Its role in OSCC has yet to be confirmed. Recently, the RTOG 0920 trial was launched to address intermediate-risk (PNI, LVI, close margin, T3 or T4a tumor, T2 with $>5 \mathrm{~mm}$ thickness, single lymph node $>3 \mathrm{~cm}$ or $\geq 2$ lymph node $<6 \mathrm{~cm}$ without ECE) OSCC patients to evaluate whether the addition of cetuximab to PORT will improve overall survival (OS) in postoperative patients.

\section{Radiation-related Toxicity \pm Chemotherapy}

Radiotherapy with or without chemotherapy to enhance disease control is associated with radiation-induced toxicity. The acute toxicity includes grade $2 / 3$ oral mucositis and dysphagia. The incidence is generally high, especially with bilateral irradiation, though is usually self-limiting (45). Common late toxicities include ORN, xerostomia, and dysphagia (46). The general impression of practitioners is that toxicity is enhanced by the use of concurrent chemotherapy with PORT. For example, the combined severe acute and late toxicity frequency in the RTOG trial 9501 reported by Cooper, et al. (3) amounted to $46 \%$ vs. $78 \%$ for PORT vs. POCRT respectively. For reasons that are not immediately apparent, the toxicity profile seems less clear in EORTC 22931; for example the severe muscular fibrosis rate was higher for POCRT (10\% vs. $5 \%)$ but severe xerostomia was lower $(14 \%$ vs. $22 \%$ ) (13). These observations underline the need to prospectively include comprehensive toxicity data collection in future trials. Spontaneous ORN is dosedependent and related to the volume of mandible receiving radiotherapy beyond 50 60 Gy (47). The incidence is generally low $(<15 \%)$ with conventional conformal radiotherapy (48) with the exception of one unexpected retrospective report in the recent literature (49). Intensity modulated radiotherapy (IMRT) is a newer method of radiotherapy that uses intensity-modulated beams that can provide multiple intensity levels allowing concave dose distributions and dose gradients with narrower margins than those possible using traditional radiotherapy (50) (Fig. 2). The incidence of ORN can be further reduced significantly by minimizing the percentage of mandibular volume exposed to $>50 \sim 60$ Gy using IMRT $(47,51,52)$. In addition, careful oral dental hygiene and smoking cessation are also important for preventing ORN. Xerostomia rates are high with conventional

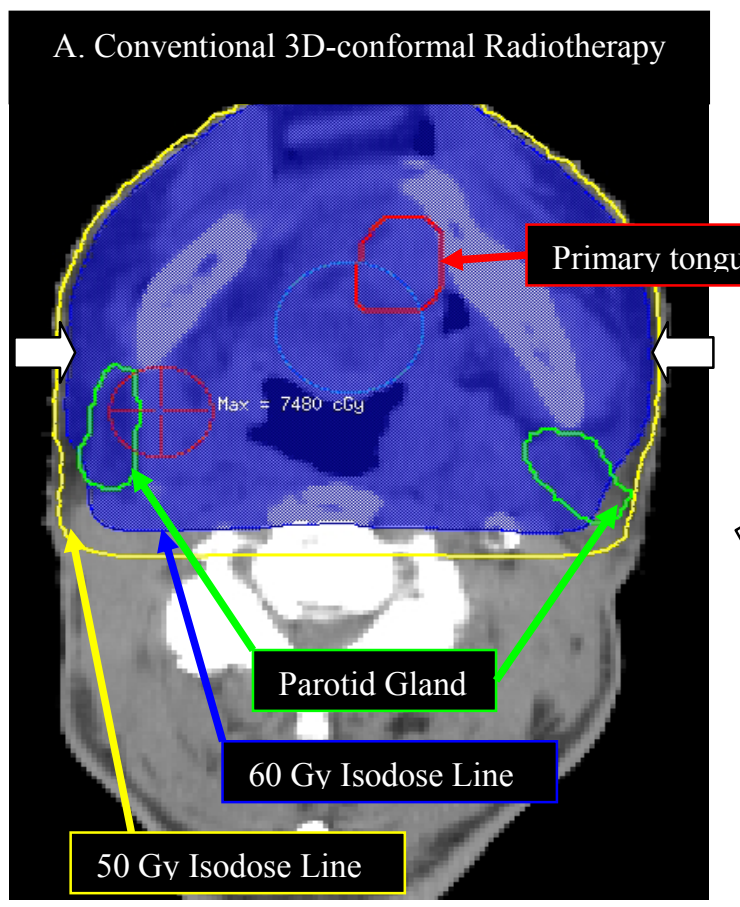

B. Intensity-modulated Radiotherapy (IMRT)

Fig. 2. Example of partial mandible and parotid-sparing IMRT vs. conventional 3D-conformal radiotherapy. Note:

-Two actual cases of T4aN0 oral tongue cancer. The dose prescription is $70 \mathrm{~Gy}$ in 35 fractions in both cases

-White arrows indicate radiation beam arrangement:

- Conventional radiotherapy: two lateral beams: $90^{\circ}$ and $270^{\circ}$

- IMRT: equally spaced 9 beam plan configuration: $200^{\circ}, 240^{\circ}, 280^{\circ}, 320^{\circ}, 0^{\circ}, 40^{\circ}, 80^{\circ}, 120^{\circ}, 160^{\circ}$

-For the same stage of disease, IMRT is able to partially spare the ipsi-lateral and totally spare the contra-lateral mandible and parotid gland to receive $60 \mathrm{~Gy}$; while both side of mandibles and almost both parotid glands received $>60$ Gy in conventional 3D-conformal radiotherapy. 
radiotherapy when salivary gland and oral cavity mucosa are inevitably included in the radiation field. IMRT has demonstrated an ability to enhance salivary sparing to reduce the rate of permanent xerostomia without compromising disease control $(45,53)$. It is also capable of reducing the rate of severe dysphagia compared to conventional radiotherapy (54).

\section{References}

1. Bessell A, Glenny AM, Furness S, Clarkson JE, Oliver R, Conway DI, et al. Interventions for the treatment of oral and oropharyngeal cancers: surgical treatment. Cochrane Database Syst Rev. 2011;9:CD006205.

2. Bernier J, Cooper JS, Pajak TF, van Glabbeke M, Bourhis J, Forastiere A, et al. Defining risk levels in locally advanced head and neck cancers: a comparative analysis of concurrent postoperative radiation plus chemotherapy trials of the EORTC (\#22931) and RTOG (\# 9501). Head Neck. 2005;27:843-50.

3. Cooper JS, Pajak TF, Forastiere AA, Jacobs J, Campbell BH, Saxman SB, et al. Postoperative concurrent radiotherapy and chemotherapy for high-risk squamous-cell carcinoma of the head and neck. N Engl J Med. 2004;350:1937-44.

4. Shrime MG, Gullane PJ, Dawson L, Kim J, Gilbert RW, Irish JC, et al. The impact of adjuvant radiotherapy on survival in T1-2N1 squamous cell carcinoma of the oral cavity. Arch Otolaryngol Head Neck Surg. 2010;136:225-8.

5. Peters LJ, Goepfert H, Ang KK, Byers RM, Maor MH, Guillamondegui $\mathrm{O}$, et al. Evaluation of the dose for postoperative radiation therapy of head and neck cancer: first report of a prospective randomized trial. Int J Radiat Oncol Biol Phys. 1993;26:3-11.

6. Langendijk JA, Slotman BJ, van der Waal I, Doornaert P, Berkof J, Leemans CR. Risk-group definition by recursive partitioning analysis of patients with squamous cell head and neck carcinoma treated with surgery and postoperative radiotherapy. Cancer. 2005;104:1408-1417. 7. Brown JS, Shaw RJ, Bekiroglu F, Rogers SN. Systematic review of the current evidence in the use of postoperative radiotherapy for oral squamous cell carcinoma. Br J Oral Maxillofac Surg. 2012;50:481-489. 8. Huang TY, Hsu LP, Wen YH, Huang TT, Chou YF, Lee CF, et al. Predictors of locoregional recurrence in early stage oral cavity cancer with free surgical margins. Oral Oncol. 2010;46:49-55.

9. Liao CT, Chang JT, Wang HM, Ng SH, Hsueh C, Lee LY, et al. Does adjuvant radiation therapy improve outcomes in pT1-3N0 oral cavity cancer with tumor-free margins and perineural invasion? Int J Radiat Oncol Biol Phys. 2008;71:371-6.

10. Huang SH, Hwang D, Lockwood G, Goldstein DP, O'Sullivan B. Predictive value of tumor thickness for cervical lymph-node involvement in squamous cell carcinoma of the oral cavity: a meta-analysis of reported studies. Cancer. 2009;115:1489-1497.

11. Liao CT, Lin CY, Fan KH, Wang HM, Ng SH, Lee LY, et al. Identification of a high-risk group among patients with oral cavity squamous cell carcinoma and pT1-2N0 disease. Int J Radiat Oncol Biol Phys. 2012;82:284-90.

12. Moergel M, Jahn-Eimermacher A, Krummenauer F, Reichert TE, Wagner W, Wendt TG, et al. Effectiveness of adjuvant radiotherapy in patients with oropharyngeal and floor of mouth squamous cell carcinoma and concomitant histological verification of singular ipsilateral cervical lymph node metastasis (pN1-state)--a prospective multicenter randomized controlled clinical trial using a comprehensive cohort design. Trials. 2009;10:118.

13. Bernier J, Domenge C, Ozsahin M, Matuszewska K, Lefèbvre JL, Greiner RH, et al. Postoperative irradiation with or without concomitant chemotherapy for locally advanced head and neck cancer. N Engl J Med. 2004;350:1945-52.

14. Cooper JS, Pajak TF, Forastiere A, Jacobs J, Fu KK, Ang KK, et al. Precisely defining high-risk operable head and neck tumors based on RTOG \#85-03 and \#88-24: targets for postoperative radiochemotherapy? Head Neck.1998;20:588-94.
15. Fan KH, Wang HM, Kang CJ, Lee LY, Huang SF, Lin CY, et al. Treatment results of postoperative radiotherapy on squamous cell carcinoma of the oral cavity: coexistence of multiple minor risk factors results in higher recurrence rates. Int J Radiat Oncol Biol Phys. 2010;77:1024-9.

16. Liao CT, Chang JT, Wang HM, Ng SH, Hsueh C, Lee LY, et al. Analysis of risk factors of predictive local tumor control in oral cavity cancer. Ann Surg Oncol. 2008;15:915-22.

17. Parsons JT, Mendenhall WM, Stringer SP, Cassisi NJ, Million RR. An analysis of factors influencing the outcome of postoperative irradiation for squamous cell carcinoma of the oral cavity. Int J Radiat Oncol Biol Phys. 1997;39:137-48.

18. Looser KG, Shah JP, Strong EW. The significance of "positive" margins in surgically resected epidermoid carcinomas. Head Neck Surg. 1978;1:107-111.

19. Batsakis JG. Surgical excision margins: a pathologist's perspective. Adv Anat Pathol. 1999;6:140-148.

20. Binahmed A, Nason RW, Abdoh AA. The clinical significance of the positive surgical margin in oral cancer. Oral Oncol. 2007;43:780784.

21. Chen PY, Chen HH, Hsiao JR, Yang MW, Hsueh WT, Tasi ST, et al. Intensity-modulated radiotherapy improves outcomes in postoperative patients with squamous cell carcinoma of the oral cavity. Oral Oncol. 2012;48:747-52.

22. Guillemaud JP, Patel RS, Goldstein DP, Higgins KM, Enepekides DJ. Prognostic impact of intraoperative microscopic cut-through on frozen section in oral cavity squamous cell carcinoma. J Otolaryngol Head Neck Surg. 2010;39:370-7.

23. Huang J, Barbera L, Brouwers M, Browman G, Mackillop WJ. Does delay in starting treatment affect the outcomes of radiotherapy? A systematic review. J Clin Oncol. 2003;21:555-63.

24. Daly ME, Le QT, Kozak MM, Maxim PG, Murphy JD, Hsu A, et al. Intensity-modulated radiotherapy for oral cavity squamous cell carcinoma: patterns of failure and predictors of local control. Int J Radiat Oncol Biol Phys. 2011;80:1412-22.

25. Langendijk JA, de Jong MA, Leemans CR, de Bree R, Smeele LE, Doornaert P, et al. Postoperative radiotherapy in squamous cell carcinoma of the oral cavity: the importance of the overall treatment time. Int J Radiat Oncol Biol Phys. 2003;57:693-700.

26. Studer G, Zwahlen RA, Graetz KW, Davis BJ, Glanzmann C. IMRT in oral cavity cancer. Radiat Oncol. 2007;2:16.

27. Murthy V, Agarwal JP, Laskar SG, Gupta T, Budrukkar A, Pai P, et al. Analysis of prognostic factors in 1180 patients with oral cavity primary cancer treated with definitive or adjuvant radiotherapy. $\mathrm{J}$ Cancer Res Ther. 2010;6:282-9.

28. Cohen EE, Baru J, Huo D, Haraf DJ, Crowley M, Witt ME, Blair EA, Weichselbaum RR, Rosen F, Vokes EE, Stenson K. Efficacy and safety of treating $\mathrm{T} 4$ oral cavity tumors with primary chemoradiotherapy. Head Neck. 2009;31:1013-21.

29. Pignon JP, le Maître A, Maillard E, Bourhis J. MACH-NC Collaborative Group. Meta-analysis of chemotherapy in head and neck cancer (MACH-NC): an update on 93 randomised trials and 17,346 patients. Radiother Oncol. 2009;92:4-14.

30. Bourhis J, Overgaard J, Audry H, Ang KK, Saunders M, Bernier $\mathrm{J}$, et al. Hyperfractionated or accelerated radiotherapy in head and neck cancer: a meta-analysis. Lancet. 2006;368:843-54.

31. Mazeron JJ, Ardiet JM, Haie-Méder C, Kovács G, Levendag P, Peiffert D, et al. GEC-ESTRO recommendations for brachytherapy for head and neck squamous cell carcinomas. Radiother Oncol. 2009;91:150-6.

32. Chakrabarti B, Ghorai S, Basu B, Ghosh SK, Gupta P, Ghosh K, et al. Late nodal metastasis in early-stage node-negative oral cavity cancers after successful sole interstitial brachytherapy: an institutional experience of 42 cases in India. Brachytherapy. 2010;9:254-9. 33. Grabenbauer GG, Rödel C, Brunner T, Schulze-Mosgau S, Strnad V, Müller RG, et al. Interstitial brachytherapy with Ir-192 low-doserate in the treatment of primary and recurrent cancer of the oral cavity and oropharynx. Review of 318 patients treated between 1985 and 1997. Strahlenther Onkol. 2001;177:338-44. 
34. Do L, Puthawala A, Syed N. Interstitial brachytherapy as boost for locally advanced $\mathrm{T} 4$ head and neck cancer. Brachytherapy. 2009;8:385-91.

35. Patra NB, Goswami J, Basu S, Chatterjee K, Sarkar SK. Outcomes of high dose rate interstitial boost brachytherapy after external beam radiation therapy in head and neck cancer--an Indian (single institutional) learning experience. Brachytherapy. 2009;8:248-54.

36. Chatani M, Tsuboi K, Yagi M, Fujiwara K, Tachimoto R, Yoshioka $\mathrm{H}$. High dose rate brachytherapy using molds after chemoradiotherapy for oral cavity cancer. Jpn J Radiol. 2012;30:40-4.

37. Lapeyre M, Bollet MA, Racadot S, Geoffrois L, Kaminsky MC, Hoffstetter S, et al. Postoperative brachytherapy alone and combined postoperative radiotherapy and brachytherapy boost for squamous cell carcinoma of the oral cavity, with positive or close margins. Head Neck. 2004;26:216-23.

38. Grimard L, Esche B, Lamothe A, Cygler J, Spaans J. Interstitial low-dose-rate brachytherapy in the treatment of recurrent head and neck malignancies. Head Neck. 2006;28:888-95.

39. Grimard L, Esche B, Lamothe A, Spaans JN. Interstitial brachytherapy in the management of persistent head and neck disease after definitive external beam radiation therapy. Brachytherapy. 2009;8:284-9.

40. Mazeron JJ, Noël G, Simon JM. Head and neck brachytherapy. Semin Radiat Oncol. 2002;12:95-108.

41. Huang SF, Cheng SD, Chien HT, Liao CT, Chen IH, Wang HM, et al. Relationship between epidermal growth factor receptor gene copy number and protein expression in oral cavity squamous cell carcinoma. Oral Oncol. 2012;48:67-72.

42. Chen IH, Chang JT, Liao CT, Wang HM, Hsieh LL, Cheng AJ. Prognostic significance of EGFR and Her-2 in oral cavity cancer in betel quid prevalent area cancer prognosis. $\mathrm{Br} \mathrm{J}$ Cancer. 2003;89:681-6.

43. Wheeler S, Siwak DR, Chai R, LaValle C, Seethala RR, Wang L, et al. Tumor epidermal growth factor receptor and EGFR PY1068 are independent prognostic indicators for head and neck squamous cell carcinoma. Clin Cancer Res. 2012;18:2278-89.

44. Bonner JA, Harari PM, Giralt J, Azarnia N, Shin DM, Cohen RB, et al. Radiotherapy plus cetuximab for squamous-cell carcinoma of the head and neck. N Engl J Med. 2006;354:567-78.

45. Bhide SA, Ahmed M, Newbold K, Harrington KJ, Nutting CM. The role of intensity modulated radiotherapy in advanced oral cavity carcinoma. J Cancer Res Ther. 2012;8 Suppl 1:S67-71.

46. Sher DJ, Thotakura V, Balboni TA, Norris CM, Haddad RI, Posner MR, et al. Treatment of oral cavity squamous cell carcinoma with adjuvant or definitive intensity-modulated radiation therapy. Int J Radiat Oncol Biol Phys. 2011;81:e215-22.

47. Tsai CJ, Hofstede TM, Sturgis EM, Garden AS, Lindberg ME, Wei Q, et al. Osteoradionecrosis and radiation dose to the mandible in patients with oropharyngeal cancer. Int J Radiat Oncol Biol Phys. 2013;85:415-20.

48. Balogh JM, Sutherland SE. Osteoradionecrosis of the mandible: a review. J Otolaryngol. 1989;18:245-50.

49. Monnier Y, Broome M, Betz M, Bouferrache K, Ozsahin M, Jaques B. Mandibular osteoradionecrosis in squamous cell carcinoma of the oral cavity and oropharynx: incidence and risk factors. Otolaryngol Head Neck Surg. 2011;144:726-32.

50. O'Sullivan B, Rumble RB, Warde P, Members of the IMRT Indications Expert Panel. Intensity-modulated radiotherapy in the treatment of head and neck cancer. Clin Oncol (R Coll Radiol). 2012;24:474-87.

51. Ben-David MA, Diamante M, Radawski JD, Vineberg KA, Stroup C, Murdoch-Kinch CA, et al. Lack of osteoradionecrosis of the mandible after intensity-modulated radiotherapy for head and neck cancer: likely contributions of both dental care and improved dose distributions. Int J Radiat Oncol Biol Phys. 2007;68:396-402.

52. Studer G, Studer SP, Zwahlen RA, Huguenin P, Grätz KW, Lütolf $\mathrm{UM}$, et al. Osteoradionecrosis of the mandible: minimized risk profile following intensity-modulated radiation therapy (IMRT). Strahlenther Onkol. 2006;182:283-8.
53. Little M, Schipper M, Feng FY, Vineberg K, Cornwall C, Murdoch-Kinch CA, et al. Reducing xerostomia after chemo-IMRT for head-and-neck cancer: beyond sparing the parotid glands. Int J Radiat Oncol Biol Phys. 2012;83:1007-14.

54. Chen WC, Hwang TZ, Wang WH, Lu CH, Chen CC, Chen CM, et al. Comparison between conventional and intensity-modulated post-operative radiotherapy for stage III and IV oral cavity cancer in terms of treatment results and toxicity. Oral Oncol. 2009;45:505-10. 55. Mishra RC, Singh DN, Mishra TK. Post-operative radiotherapy in carcinoma of buccal mucosa, a prospective randomized trial. Eur J Surg Oncol. 1996;22:502-4. 